\title{
Screening of Sacrificial Excipients for Arresting Devitrification of Itraconazole from Solid Dispersion
}

\author{
İtrakonazolün Katı Dispersiyondan Devitrifikasyonunu Önlemek için \\ Amaca Yönelik Yardımcı Maddelerin Taranması
}

\author{
(D) Bhargavi M. PATEL, (D) Mukesh C. GOHEL, (D) Vaishali T. THAKKAR*, (D) Lalji H. BALDANIYA, (D) Ruby R. CHRISTIAN, (D) Tejal R. GANDHI \\ Gujarat Technological University, Anand Pharmacy College, Anand, Gujarat, India
}

\begin{abstract}
Objectives: The aim of the present investigation was to develop a solid dispersion of itraconazole (ITR) using sacrificial excipients like pregelatinized starch and spray-dried lactose alongside hydroxypropyl methylcellulose and Poloxamer 188, thereby arresting the conversion of the amorphous form of ITR to crystalline form, and to assess the dissolution stability of an amorphous form of the drug during short-term storage.

Materials and Methods: ITR-loaded solid dispersions were prepared by kneading. Formulation optimization was achieved by using a $2^{4}$ full factorial design on the basis of cumulative percent drug released at $t_{30}, t_{60}$, and $t_{120}$ min. An artificial neural network (ANN) was also applied as a statistical tool for obtaining better predictive ability and the outcomes of the ANN were compared with that of Design-Expert software.

Results: The spectral data revealed no drug-carrier interactions. The P-X-ray diffraction study of the optimized batch showed a decrease in the crystallinity of drug as compared to the untreated drug. The in vitro dissolution studies of the optimized batch showed higher dissolution ( $92 \%$ at $120 \mathrm{~min}$ ) in comparison to the other formulations. The dissolution stability study was performed at $40^{\circ} \mathrm{C}$ and $75 \%$ relative humidity for 90 days for the optimized formulation. The results of the optimized batch showed insignificant changes in cumulative percentage drug release during storage. Conclusion: Dissolution stability could be attributed to the presence of sacrificial excipients as they tend to absorb moisture during storage and possibly get converted into crystalline form, thereby minimizing the recrystallization of ITR.
\end{abstract}

Key words: Solid dispersion, itraconazole, ANN, sacrificial excipients, devitrification

Öz

Amaç: Mevcut araştırma, prejelatinize nişasta, püskürterek kurutulmuş laktoz yanısıra hidroksipropil metilselüloz ve Poloxamer 188 gibi amaca yönelik yardımcı maddeler kullanılarak itrakonazolün (ITR) katı dispersiyonunu geliştirmeyi ve böylece ITR'nin amorf formunun kristal formuna dönüștürülmesini durdurmayı ve kısa süreli depolamada etkin maddenin amorf formunun çözülme stabilitesini değerlendirmeyi amaçlamıştır.

Gereç ve Yöntemler: ITR yüklü katı dispersiyonlar hamur etme metoduyla hazırlandı. Formülasyon optimizasyonu, $t_{30}, t_{60}$ ve $t_{120}$ dakikada salınan kümülatif yüzde etkin maddeyi baz alarak $2^{4}$ tam faktörlü tasarım kullanılarak elde edilmiștir. Yapay sinir ağı (YSA), daha iyi bir tahmin yeteneği elde etmek için istatistiksel bir araç olarak uygulanmış ve YSA'nın sonuçları, design expert yazılımınınkilerle karșılaştırılmıştır.

Bulgular: Spektral veri ilaç taşıyıcı etkileşimi göstermemiştir. Optimize edilmiş partinin P-X-ışını difraksiyon çalışması, işlem görmemiş etkin maddeye kıyasla etkin maddenin kristalliğinde azalma göstermiştir. Optimize edilmiş partinin in vitro çözünme çalışmaları, diğer formülasyonlara kıyasla en yüksek çözünme (120 dakikada \%92) göstermiştir. Çözünme stabilitesi çalıșması, optimize edilmiş formülasyon için 90 gün boyunca $40^{\circ} \mathrm{C}$ 'de ve \%75 bağıl nem yapılmıştır. Optimize edilmiş partinin sonuçları, depoda kümülatif yüzde etkin madde salımında önemsiz değişiklikler göstermiştir.

Sonuç: Çözünme stabilitesi, amaca yönelik yardımcı maddelerin varlığında depolamadaki nemi absorbe etme eğiliminde olduklarından ve muhtemelen bu nem ile kendilerinin kristalli bir forma dönüșmesine ve ITR'nin yeniden kristalleșmesini en aza indirmesine bağlanabilir.

Anahtar kelimeler: Katı dispersiyon, itrakonazol, YSA, amaca yönelik madde, devitrifikasyon

*Correspondence: E-mail:vtthakkar@rediffmail.com, Phone: 9724431131 ORCID-ID: orcid.org/0000-0000-6332-7703

Received: 10.01.2018, Accepted: 05.04.2018

TTurk J Pharm Sci, Published by Galenos Publishing House. 


\section{INTRODUCTION}

More than $40 \%$ of newly discovered active pharmaceutical ingredients (APIs) fail to enter the market due to low aqueous solubility. Micronization, $\mathrm{pH}$ modification, hydrotropy, and solid dispersion have been examined for improvement of apparent drug solubility in aqueous medium, API release rate, and possibility of bioavailability. Solid dispersions can be incorporated into tablets, capsules, bioadhesive film, implants, and dry powder inhalers. ${ }^{2}$ The other merits of solid dispersion include generation of fine particles of APIs without excessive use of energy and availability of a variety of formulation options.

The main limitation of a solid dispersion is, as reported in the literature, its physical stability and recrystallization of APIs on standing, due to absorption of moisture by the carrier and particle growth. The phenomenon of reverse crystallization of APIs results in retarded API dissolution. ${ }^{3}$ Maintenance of the amorphous state of the drug in a dosage form is always a challenge to the formulators. This is one of the reasons for the availability of a limited number of formulations on the market.

We hypothesized that if amorphous excipients are added to a solid dispersion containing amorphous APIs then the probability of recrystallization of APIs will be arrested to a certain extent due to competition between the APIs and excipient. Such excipients are referred to as sacrificial excipients in the present investigation. This term is coined from the widely used term sacrificial antioxidants (ascorbic acid and others), which are added to formulations containing oxygen-sensitive APIs.

The example amorphous excipients are spray-dried lactose, pregelatinized starch, low-substituted hydroxypropyl ether of cellulose, and Neusilin. The sacrificial excipient will preferentially absorb moisture on standing and preferentially get converted in crystalline form and afford protection to the amorphous physical state of the API. In the present investigation, the use of quality by design is also demonstrated to speed up the formulation development work at the plant. Comparison is also done between the use of design of experiments (DoE) and artificial neural network (ANN).

The main objectives of the present study were to improve the apparent solubility of itraconazole (ITR) and to test the proposed hypothesis of using sacrificial amorphous excipients for imparting dissolution stability to APIs during storage.

\section{MATERIALS AND METHODS}

\section{Materials}

ITR was received as a gratis sample from Alembic Pharmaceuticals (Baroda, India). The samples of hydroxypropyl methylcellulose (HPMC E5) and pregelatinized starch were procured from Colorcon Asia Pvt. Ltd. (Goa, India). Spray-dried lactose was procured from Signet Chemicals (Mumbai, India). Poloxamer 188 was purchased from BASF (Mumbai, India) and the solvents used were obtained from Astron Chemicals Pvt. Ltd., (Ahmedabad, India)

\section{Preparation of solid dispersion by kneading method}

Solid dispersions of ITR were prepared by kneading. Accurately weighed quantities of HPMC E5, Poloxamer 188, and sacrificial excipients (spray-dried lactose or pregelatinized starch) were mixed with a sufficient quantity of water to obtain a smooth and homogeneous paste; after that a weighed quantity of ITR was added to the paste and kneaded for 30 min. Finally the paste was dried in an oven at $45^{\circ} \mathrm{C}$ for $3 \mathrm{~h}$ and then passed through sieve \#100. The samples were stored in a screw-capped glass vial until use. ${ }^{4}$

\section{Experimental design}

The concentrations of spray-dried lactose $\left(X_{1}\right)$, pregelatinized starch $\left(X_{2}\right)$, HPMC E5 $\left(X_{3}\right)$, and Poloxamer $188\left(X_{4}\right)$ were selected as independent variables in a $2^{4}$ full factorial design. All the other formulation factors were kept constant throughout the experiment. The percentages of drug dissolved at $30\left(Y_{1}\right), 60$ $\left(Y_{2}\right)$, and $120\left(Y_{3}\right)$ min in $0.1 \mathrm{~N} \mathrm{HCl}$ were selected as dependent variables. Design-expert software (version 9.0.0.7) was used for creating the mathematical models. ${ }^{5}$ The design layout with the results is shown in Table 1 . Polynomial models including interaction terms were generated for all the response variables. The full polynomial equation is shown below (Equation 1).

$Y=b_{0}+b_{1} X_{1}+b_{2} X_{2}+b_{3} X_{3}+b_{4} X_{4}+b_{12} X_{1} X_{2}+b_{13} X_{1} X_{3}+b_{14} X_{1} X_{4}+$ $b_{23} x_{2} X_{3}+b_{24} x_{2} x_{4}+b_{34} x_{3} x_{4}+b_{1234} x_{1} x_{2} x_{3} x_{4}$

Here $b_{0}$ is the intercept representing the arithmetic average of all quantitative outcomes of factorial runs; $b_{1}$ to $b_{4}$ are the main effects. The terms $b_{12}, b_{13}, b_{14}, b_{23}, b_{24}$, and $b_{34}$ represent the interaction terms. The statistical validity of the model was established on the basis of analysis of variance. Subsequently, feasibility and grid searches were performed to locate the composition of the optimum formulation. Contour plots were also constructed in MS-Excel environment using the output files generated by the design-expert software.

\section{Artificial neural network}

ANN is a machine-based computational technique that attempts to simulate some of the neurological processing ability of the human brain. Fundamentally, ANNs are interconnected networks of processing units termed as 'neurons', which are responsible for the completion of the decision-making process. They have the ability to discern complex and latent patterns in the information presented to them. This feature of ANNs proves they are a powerful tool for modeling and predictive purposes and offers great potential for application in a variety of disciplines. ANNs have attracted the attention of many computer scientists and have been successfully applied to solve a multitude of problems in diverse areas of science, engineering, and business. ${ }^{6}$

A three-layer network with a different activation function was applied in this study. NeuroSolutions version 7.0.0 evaluation software was downloaded from NeuroDimension, Inc (www. nd.com). The independent variables $X_{1}, X_{2}, X_{3}$, and $X_{4}$ were used as inputs and the responses recorded were cumulative drug release at 30,60 , and $120 \mathrm{~min}$. Generally, the neural network methodology has several empirically determined parameters. These include the number of iterations or epochs, the processing 
element, learning rate, and momentum terms. The optimum values for ANN parameters were evaluated by obtaining those values that yielded the lowest prediction error. The multilinear perceptron network model was selected from the customized new network. Different functions like TanhAxon, SigmoidAxon, LinearTanAxon, LinearSigmoidAxon, BiasAxon, LinearAxon, and Axon were used to predict the output response. ${ }^{7}$

\section{Evaluation parameters}

\section{Drug content}

Solid dispersions equivalent to $10 \mathrm{mg}$ of ITR were weighed accurately and dissolved in a suitable quantity of methanol. The drug content was analyzed at $260 \mathrm{~nm}$ by ultraviolet spectrophotometer (Shimadzu, Japan). Each sample was analyzed in triplicate.

\section{In vitro drug release study}

Dissolution experiments were conduct on the untreated drug and solid dispersion. The in vitro release test was performed using a USP type-I (basket type) dissolution apparatus (Electrolab TDT 08L, India). The dissolution medium was 0.1 $\mathrm{N} \mathrm{HCl}(\mathrm{pH} 1.2)$ maintained at a temperature of $37 \pm 1^{\circ} \mathrm{C}$ with a paddle speed of $100 \mathrm{rpm}$. The powdered samples (sieved through a 100- $\mu \mathrm{m}$ sieve) of pure drug and solid dispersion batches, equivalent to $100 \mathrm{mg}$ of ITR, were separately added to the dissolution vessels while stirring. Samples $(5 \mathrm{~mL})$ were drawn at 30, 60, and $120 \mathrm{~min}$ and fresh dissolution medium ( $5 \mathrm{~mL}$ ) was added after sampling to maintain sink condition. The samples were immediately filtered through $0.45-\mu \mathrm{m}$ filters. The first $2 \mathrm{~mL}$ of the filtrate was discarded and the samples were assayed for drug content after appropriate dilution with

Table 1. Variables, their levels, and responses in $2^{4}$ full factorial design

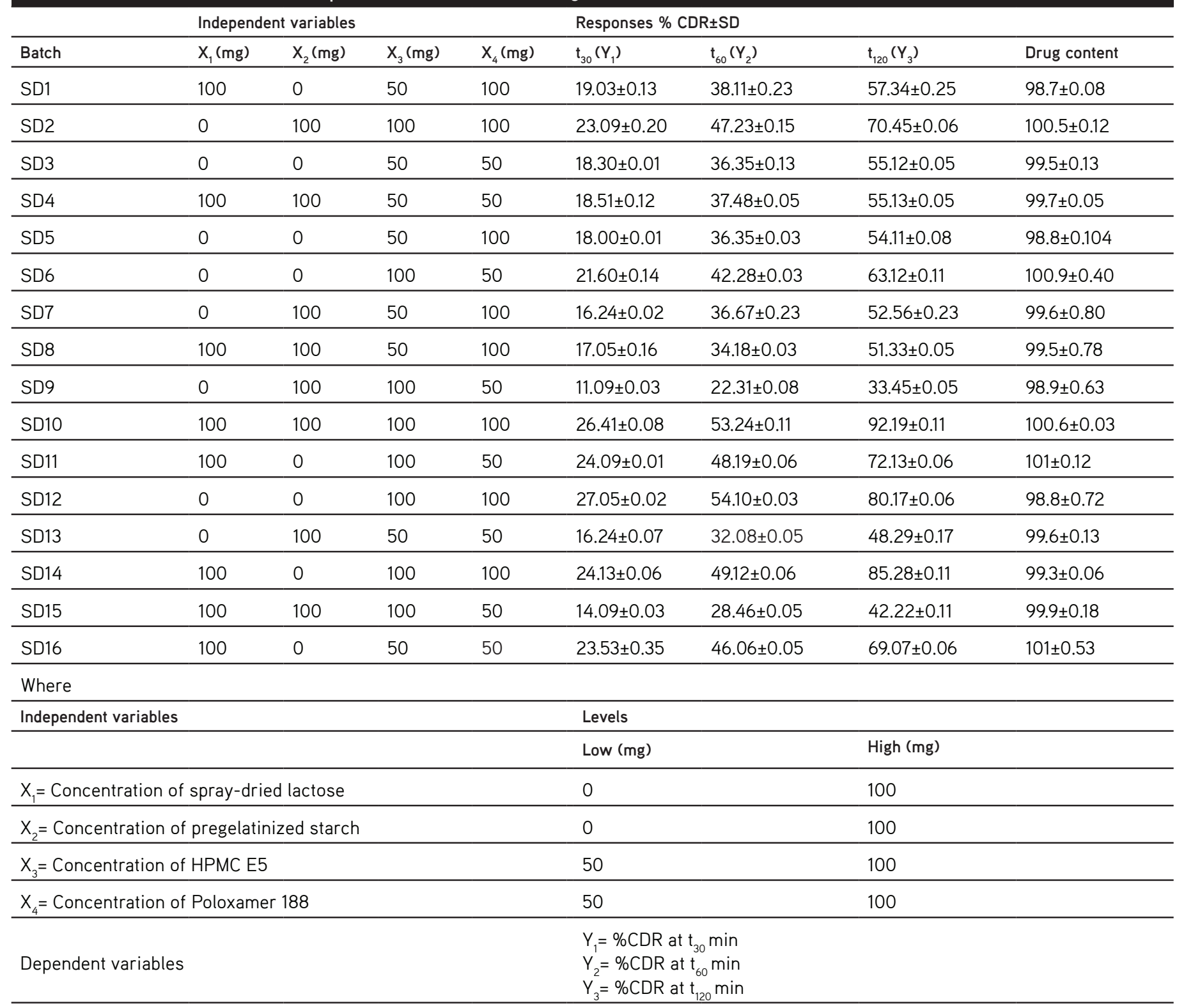

SD: Standard deviation 
the dissolution medium. The cumulative amounts of the drug dissolved (expressed as \% of the total drug added) were plotted as a function of time to produce the dissolution profiles. ${ }^{8}$

\section{Fourier transform infrared spectroscopy}

Spectroscopy was conducted using an fourier transform infrared (FTIR) spectrophotometer (Spectrum GX-FT-IR, PerkinElmer, USA) for the untreated ITR and optimized batch of ITR solid dispersion. The spectrum was recorded in the range of $4000-400 \mathrm{~cm}^{-1}$. The procedure consisted of dispersing a sample in $\mathrm{KBr}$ followed by gentle mixing. The spectrum was scanned at a resolution of $0.15 \mathrm{~cm}^{-1}$ and scan speed was 20 scan/s.

\section{Differential scanning calorimetry}

A differential scanning calorimeter (DSC) (DSC-PYRIS-1, Phillips, Netherlands) was used to study the thermal behavior of the untreated ITR and optimized batch of ITR solid dispersion. The experiments were performed in a dry nitrogen atmosphere. The samples (2-4 $\mathrm{mg}$ ) were heated in hermetically sealed flatbottomed aluminum pans under nitrogen flow $(20 \mathrm{~mL} / \mathrm{min})$ at a scanning rate of $10^{\circ} \mathrm{C} / \mathrm{min}$ from $25^{\circ} \mathrm{C}$ to $200^{\circ} \mathrm{C}$. Empty aluminum pans were used as the reference standard.

\section{$X$-ray diffraction}

The X-ray diffraction (XRD) study was carried out to characterize the physical form of ITR in samples of untreated ITR and optimized batch of ITR solid dispersion. Vacuum grease was applied onto the glass slide to stick the sample. The sample was allowed to spread on the glass slide in approximately 0.5 $\mathrm{mm}$ thickness. The slide was then placed vertically at $0^{\circ}$ angle in the X-ray diffractometer (X'Pert Model, Phillips, Netherlands) so that the $X$-ray beam fell on it properly. The results were recorded over a range of $0-90^{\circ}(2 \theta)$ using the Cu-target X-ray tube and $\mathrm{Xe}$-filled detector. The operating conditions were as follows: voltage $40 \mathrm{kV}$, current $20 \mathrm{~mA}$, scanning speed 1/ min, temperature of acquisition: room temperature, detector: scintillation counter detector, and sample holder: nonrotating holder.

\section{Moisture uptake study}

Accurately weighed amounts of optimized solid dispersion (ITR + HPMC E5 + Poloxamer 188), solid dispersion with sacrificial excipient (ITR + HPMC E5 + Poloxamer 188 + PGS + spray-dried lactose), and also amorphous excipients PGS and spray-dried lactose were exposed to $75 \% \mathrm{RH}$ for a fixed period of time.
The stated humidity was obtained using saturated aqueous solution of sodium chloride in a sealed desiccator at $40 \pm 1^{\circ} \mathrm{C}$. The samples were observed in two different conditions, i.e., with a packaging system (samples sealed with aluminum foil) and without a packaging system.

\section{Stability study}

Short-term dissolution stability was studied under accelerated stability condition. The optimized batch with and without sacrificial excipient was stored at ambient conditions in capped amber vials $\left(40^{\circ} \mathrm{C} / 75 \% \mathrm{RH}\right)$. Samples were evaluated at an interval of 30,60 , and 90 days for drug content and in vitro release characteristics study. In addition, further confirmation of stability was obtained by performing an XRD study so as to confirm the amorphous property of the drug during storage. ${ }^{9}$

\section{RESULTS AND DISCUSSION}

\section{Drug content}

The drug contents of the solid dispersions were found to be in the range of $98.7 \%-101.3 \%$ (Table 1), which is acceptable according to the United States Pharmacopeia. ${ }^{10}$

\section{In vitro release study}

The cumulative drug release for the batches (SD1 to SD16) at $t_{120}$ showed a wide variation of $33 \%$ to $98 \%$ (Table 1, Figure 1a). The fitted polynomial equations (full and reduced model) relating the response at $t_{30}, t_{60}$, and $t_{120}$ to the transformed factors are shown in Table 2 . The polynomial equations can be used to draw conclusions after considering the magnitude of coefficient and the mathematical sign it carries, i.e., positive or negative. The significance level of coefficients, which was found to be $>0.05$, was omitted from the full model equation to generate the reduced model equation for all three responses. The coefficients found to be significant at $p$ value less than 0.05 were retained in the reduced model. Table 2 shows the results of the regression analysis. The high values of correlation coefficients of \%CDR at $t_{30}, t_{60}$, and $t_{120}$ indicate a good fit. Table 3 shows the results of ANOVA. The $p$ value is less than 0.05 for all three responses. It can, therefore, be concluded that at least one of the independent variables influences the release of the drug from the solid dispersion.

The change in \%CDR at $t_{30}, t_{60}$, and $t_{120}$ as a function of $X_{3}$ and $X_{4}$ is depicted in the form of a response surface plot (Figure $1 b)$ based on the full factorial design. Low level of $X_{3}$ and high Table 2. Results of regression analysis

\begin{tabular}{|c|c|c|c|c|c|c|c|c|c|c|c|}
\hline Response & $b_{0}$ & $b_{1}$ & $b_{2}$ & $b_{3}$ & $\mathrm{~b}_{4}$ & $b_{1} b_{2}$ & $\mathrm{~b}_{1} \mathrm{~b}_{3}$ & $\mathrm{~b}_{1} \mathrm{~b}_{4}$ & $b_{2} b_{3}$ & $b_{2} b_{4}$ & $b_{3} b_{4}$ \\
\hline Reduced model for $t_{30}$ & 20.01 & 1.55 & 1.58 & -2.02 & - & 2.26 & - & - & 1.43 & - & - \\
\hline Full model for $t_{60}$ & 40.03 & 3.07 & 3.31 & -3.84 & 1.81 & 4.48 & -1.45 & -0.19 & 2.79 & -1.52 & 0.34 \\
\hline Reduced model for $t_{60}$ & 40.03 & 3.07 & 3.31 & -3.84 & 1.81 & 4.48 & - & - & 2.79 & - & - \\
\hline
\end{tabular}


level of $X_{1}, X_{2}$, and $X_{4}$ were found to be favorable conditions for obtaining faster dissolution. The multiple linear regression analysis (Table 2 ) revealed that coefficients $X_{1}, X_{2}$, and $X_{4}$ are positive and $X_{3}$ is negative. This indicates that on increasing factor $X_{1}, X_{2}$, and $X_{4}$, the drug release rate at each time point increases. A higher amount of HPMC may lead to gelation..1 This is due to the tendency of HPMC E5 to form a hydrogel that slowly erodes in water, which probably explains the delayed dissolution. In contrast, poloxamer is a water-soluble nonionic surface-active agent and has been used in solid dispersions to improve the apparent solubility of APIs. It is proposed that the amorphous state of ITR in Poloxamer 188 solid dispersions and the solubilizing effect of poloxamer are attributable to the high dissolution rate. ${ }^{12}$ Pregelatinized starch and spraydried lactose improved the dissolution of ITR by virtue of its ability to arrest the devitrification process, thereby keeping the drug in amorphous state. Checkpoint batches C1, C2, and C3 were prepared as per the composition given in Table $4 a$. The theoretical \% cumulative drug release at $t_{120}$ of batches C1, C2, and C3 was 92.30\%, 92.17\%, and 92.38\%, respectively. The experimental values were $92.22 \%, 92.00 \%$, and $92.16 \%$,

a
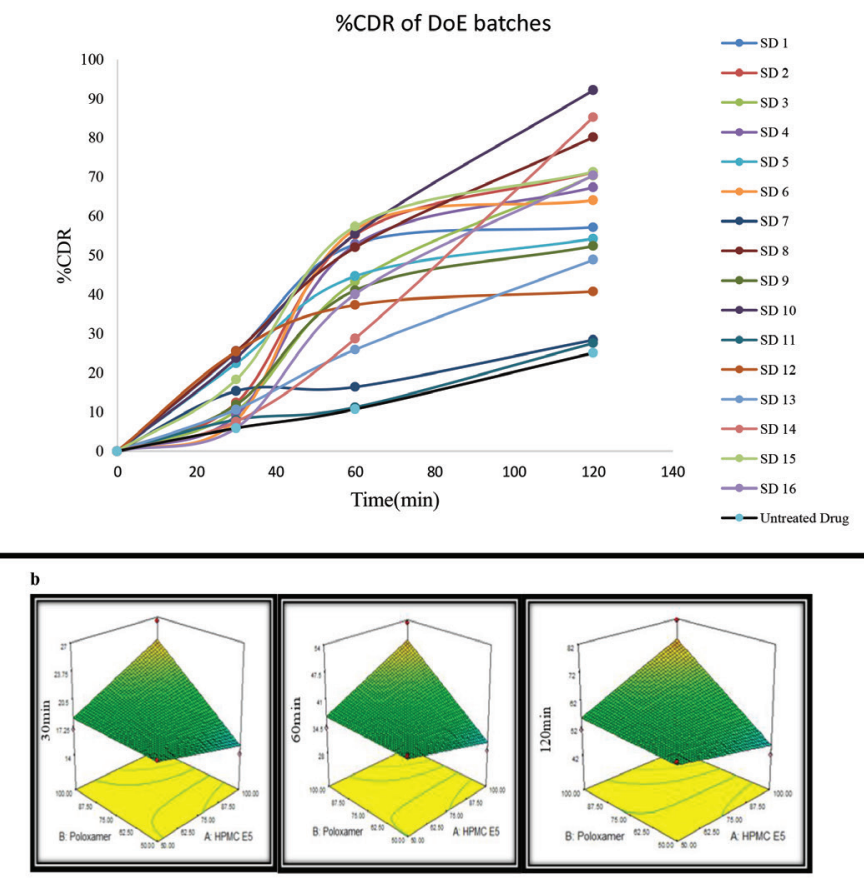

c

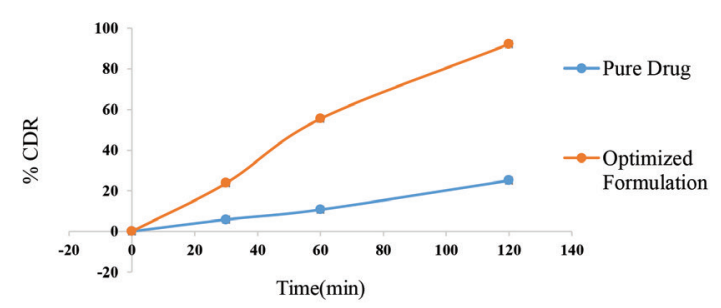

Figure 1. a) \%CDR of design of experiments batches, b) response surface plot of \%CDR at 30,60, and $120 \mathrm{~min}, \mathrm{c}$ ) dissolution profile of pure drug itraconazole and optimized formulation respectively, for the three batches (Table $4 \mathrm{~b}$ ), which are in good agreement with theoretical values. This confirms the validity of the model. The optimized batch obtained from the solutions of DoE was $99.21 \mathrm{mg}$ of HPMC E5, $98.90 \mathrm{mg}$ of Poloxamer 188, 100 $\mathrm{mg}$ of pregelatinized starch, and $100 \mathrm{mg}$ of spray-dried lactose, which met the set dissolution criterion, i.e. more than $75 \%$ drug release at $120 \mathrm{~min}$. The dissolution profile comparison of pure ITR with the optimized formulation clearly indicated enhanced solubility of the drug in solid dispersion form rather than in pure form as seen in Figure 1c.

\section{Overlay plot}

The US Food and Drug Administration (FDA) insists that while submitting the ANDA application the design space shall be submitted. Hence, the design space was generated by overlapping the three contour plots (Figure 2). The area in the right top corner indicates the design space. It is the space within which if variations occur then the FDA should not be approached for SUPAC, i.e., scale-up and postapproval changes.

\section{Artificial neural network}

In the ANN, the training data set (a couple of data points are picked from the experimental runs) was used to develop a mathematical model and thereafter the test data (the data points not included in training) were uploaded for prediction. Then the observed value of response and computed values of the selected responses were compared. The difference between the two responses is expressed as root mean square of error (RMSE). If the model is perfect, the value of RMSE is zero. A low value of RMSE is an indication of better fit. The data collected were entered into the Neurosolutions software and for each response ANN was run to get the values of RMSE. 6,7 The number of epochs needed by the various options and the MSE values for all responses are summarized in Table 5. The TanhAxon function showed the lowest RMSE value for all the responses. Moreover, 18, 18, and 15 epochs were required by the software to arrive at the minimum mean square of error of

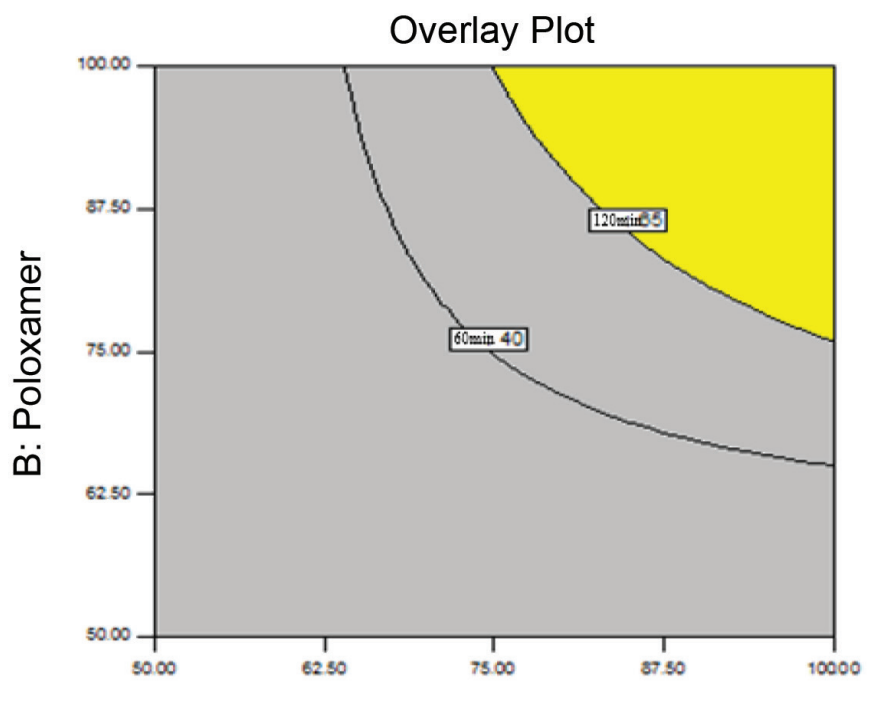

A: HPMC E5

Figure 2. Overlay plot 
$0.07,1.972 \times 10^{-25}$, and 0.017 for all three responses, respectively, when the TanhAxon option was selected in the software. The value of MSE is very close to zero. When the observed value of a response and a calculated value of response are exactly identical MSE is equal to zero. It means that the fit is perfect (the predicted value is very close to the observed value). The software generally achieves this by an iteration technique. Comparison of RMSE in the DoE and the ANN showed that the ANN serves as a better predictive tool as shown in Table 6 .

\section{FTIR study}

The FTIR spectrum of pure ITR and that of optimized solid dispersions are shown in Figures $3 a$ and $3 b$, respectively. The
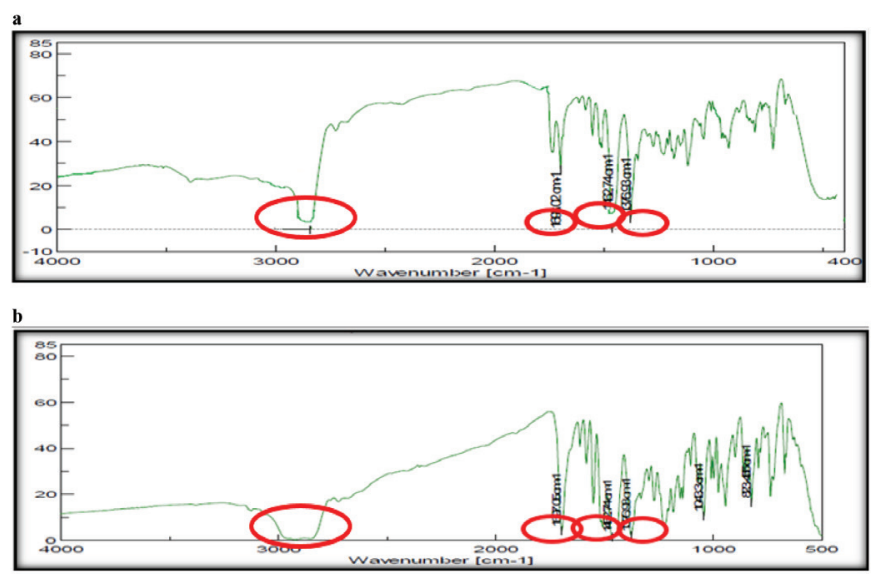

Figure 3. a, b) Fourier transform infrared spectra of itraconazole and itraconazole solid dispersion

\section{Table 3. The results of ANOVA*}

\begin{tabular}{|c|c|c|c|c|c|c|c|}
\hline Response & Df & SS & MS & $\mathrm{F}$ & $\begin{array}{l}P \\
\text { value }\end{array}$ & $\mathrm{R}^{2}$ & Model \\
\hline$t_{30}$ & 10 & 288.49 & 28.85 & 5.99 & 0.030 & 0.922 & \multirow{3}{*}{ Significant } \\
\hline$t_{60}$ & 10 & 1134.14 & 113.41 & 6.44 & 0.02 & 0.928 & \\
\hline$t_{120}$ & 10 & 2554.98 & 255.50 & 5.85 & 0.03 & 0.921 & \\
\hline
\end{tabular}

*ANOVA indicates analysis of variance, Df: Degrees of freedom, SS: Sum of squares, MS: Mean of squares, F: Fisher's ratio, $R^{2}$ : Regression coefficient, FM: Full model, RM: Reduced model

\section{Table 4a. Check point batches composition}

\begin{tabular}{lllll} 
Batch & $\mathrm{X}_{1}(\mathrm{mg})$ & $\mathrm{X}_{2}(\mathrm{mg})$ & $\mathrm{X}_{3}(\mathrm{mg})$ & $\mathrm{X}_{4}(\mathrm{mg})$ \\
\hline C1 & 100 & 100 & 99.21 & 98.90 \\
\hline C2 & 100 & 100 & 98.83 & 98.90 \\
\hline C3 & 100 & 100 & 98.83 & 99.28 \\
\hline
\end{tabular}

spectrum of ITR showed characteristic bands at 2935 and 2833 $\mathrm{cm}^{-1}$ (O-H stretching), $3320 \mathrm{~cm}^{-1}\left(\mathrm{~N}-\mathrm{H}\right.$ stretching), $1697 \mathrm{~cm}^{-1}$ ( $\mathrm{C}=\mathrm{O}$ stretching), 1375 and $1465 \mathrm{~cm}^{-1}(\mathrm{O}-\mathrm{H}$ in plane bending), $1040 \mathrm{~cm}^{-1}\left(\mathrm{O}-\mathrm{H}\right.$ out of plane bending), and 722 and $749 \mathrm{~cm}^{-1}$ (out of plane bending for $\mathrm{N}-\mathrm{H}$ ). If we focus on the spectra of the solid dispersions, then prominent peaks of the drug are seen at $2935 \mathrm{~cm}^{-1}$ for $\mathrm{O}-\mathrm{H}$ stretching, which is shifted to lower frequency of $2922 \mathrm{~cm}^{-1}$ in its kneaded particles with the same ratio. The reason for this observation might be interpreted as a consequence of $\mathrm{O}-\mathrm{H}$ stretching, which was found to be very weak in its kneaded particles. These suggest that there must be strong hydrogen bonding of the drug with HPMC E-5. It can be inferred that ITR molecules were entrapped in the matrix structure of HPMC E-5 and its physical movement in the matrix was minimum and so re-aggregation and recrystallization chances were minimum with the HPMC E- $5 .^{13}$

\section{DSC thermogram}

The DSC curves obtained for untreated ITR and solid dispersions are shown in Figures $4 \mathrm{a}$ and $4 \mathrm{~b}$. Pure ITR showed a sharp endotherm at $167.38^{\circ} \mathrm{C}$ corresponding to its melting point. The DSC thermogram of ITR solid dispersion (Figure 4b) shows characteristic peaks at $50.17^{\circ} \mathrm{C}$ and $216.42^{\circ} \mathrm{C}$ corresponding to melting point of Poloxamer 188 and HPMC E5, respectively. Absence of a characteristic peak of the drug was noted in solid dispersions. These suggest that the physical state of the drug has been changed from crystalline to amorphous form. It is well known that transforming the physical state of the drug to amorphous or partially amorphous state leads to a high energy
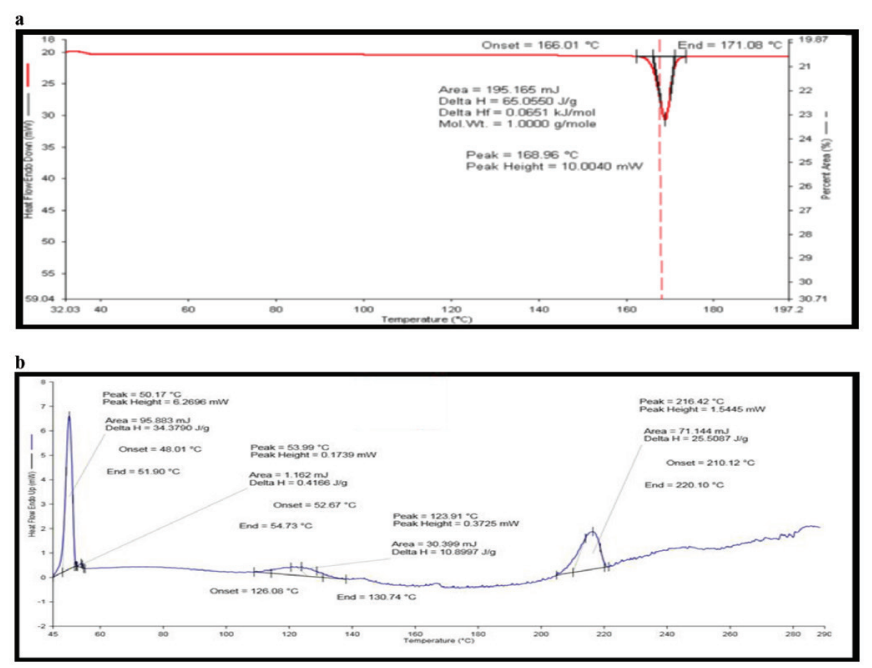

Figure 4. Differential scanning calorimeter thermographs of a) itraconazole, b) itraconazole physical mixture

Table 4b. Check point batches response

\begin{tabular}{|c|c|c|c|c|c|c|c|c|c|}
\hline \multirow{2}{*}{ Batch } & \multicolumn{3}{|c|}{$t_{30}(\%$ CDR $)$} & \multicolumn{3}{|c|}{$\mathrm{t}_{60}(\% \mathrm{CDR})$} & \multicolumn{3}{|c|}{$t_{120}(\%$ CDR $)$} \\
\hline & Predicted & Cal. & Error\% & Predicted & Cal. & Error\% & Predicted & Cal. & Error\% \\
\hline $\mathrm{C} 1$ & 23.94 & 23.75 & 0.22 & 48.26 & 48.00 & 0.53 & 92.30 & 92.22 & 0.46 \\
\hline C3 & 23.96 & 23.85 & 0.45 & 48.31 & 48.15 & 0.33 & 92.38 & 92.16 & 0.29 \\
\hline
\end{tabular}


state and high disorder, resulting in enhanced solubility and faster dissolution. ${ }^{14}$

\section{$X R D$}

The XRD pattern of untreated ITR, solid dispersions, and solid dispersion after the stability study of 90 days are shown in Figures $5 a, 5 b$, and $5 c$, respectively. The XRD scan of pure ITR showed intense peaks of crystallinity, whereas the XRD pattern of prepared solid dispersion and solid dispersion after stability exhibited a reduction in both number and intensity of peaks compared to the plain ITR, indicating a decrease in crystallinity or partial amorphization of the drug in its kneaded form. Untreated ITR drug powder showed sharp intense peaks
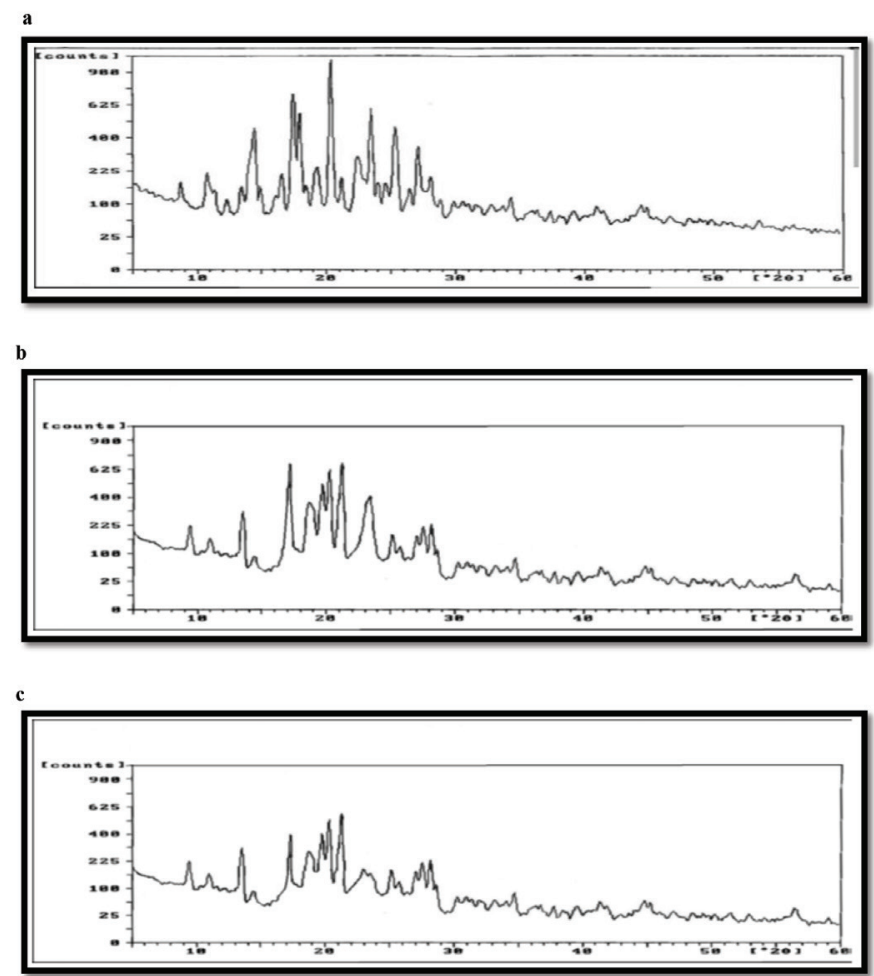

Figure 5. X-ray diffraction patterns of a) untreated itraconazole, b) itraconazole solid dispersion, c) itraconazole solid dispersion after 90-day stability study at diffraction angles of $2 \theta, 7.62,10.33,14.23,15.41,18.66,19.73$, $20.70,21.86,22.73,23.61,25.03,27.61$, and 28.62. These sharp peaks were present in the diffractograms of all the samples. The number of peaks and peak height in the diffractograms of solid dispersion decreased compared to that of untreated ITR crystalline powder. Relative crystallinity at $2 \theta$ angle 20.70 was found to be 0.675 . This indicates a decrease in crystallinity or amorphization of the drug. After 90 days of stability study at $40^{\circ} \mathrm{C} \pm 75 \% \mathrm{RH}$, the same XRD pattern was obtained, indicating that the solid dispersion was stable and the drug was in amorphous state.

\section{Moisture uptake study}

It is well understood that amorphous drugs formulated in a solid dispersion tend to undergo devitrification upon storage at high temperature and humidity. ${ }^{4}$ The optimized solid dispersion, without sacrificial excipients, was found to be highly hydroscopic (>30\% water uptake) in nature at $75 \% \mathrm{RH}$. As the exposure time to the humidity was increased, the moisture content also increased. The plasticizing effect of absorbed moisture can reduce the $T_{\mathrm{g}}$ of an amorphous substance and lead to further instability. Hence, a decrease in dissolution rate is expected on long-term storage. The samples of SD containing PGS and spray-dried lactose picked up less moisture. The results of the moisture uptake study of SD with and without sacrificial excipients and amorphous excipients (PGS and spray-dried lactose) are shown in Table 7 . The data reveal that presence of sacrificial excipients absorbs the moisture in preference to the amorphous drug, thereby stabilizing the solid dispersion during storage. The improved stability of amorphous ITR in the presence of sacrificial excipient could be explained on the basis of a combination of several effects: (a) elevation of $T_{\mathrm{g}}$;

Table 6. RMSE of DoE and ANN

\begin{tabular}{lll} 
Response & RMSE (DoE)-EXCEL & RMSE (ANN) \\
\hline $1\left(t_{30}\right)$ & 5.084 & 0.070 \\
\hline $2\left(t_{60}\right)$ & 10.649 & $1.972 \times 10^{-25}$ \\
\hline $3\left(t_{120}\right)$ & 15.984 & 0.017 \\
\hline
\end{tabular}

RMSE: Root mean square of error, DoE: Design of experiments, ANN: Artificial neural network

Table 5. RMSE values and number of epochs for each response variable

\begin{tabular}{|c|c|c|c|c|c|c|}
\hline \multirow{2}{*}{ Function/parameter } & \multicolumn{2}{|c|}{$Y_{1}$ response } & \multicolumn{2}{|c|}{$Y_{2}$ response } & \multicolumn{2}{|c|}{$Y_{3}$ response } \\
\hline & RMSE & No. of epochs & RMSE & No. of epochs & RMSE & No. of epochs \\
\hline TanhAxon & 0.070 & 18 & $1.972 \times 10^{-25}$ & 18 & 0.017 & 15 \\
\hline LinearTanAxon & 0.0707 & 19 & 0.070 & 25 & 0.031 & 19 \\
\hline LinearSigmoidAxon & 0.827 & 57 & 0.828 & 1000 & 0.759 & 896 \\
\hline LinearAxon & 0.262 & 4 & 0.244 & 5 & 0.223 & 6 \\
\hline Axon & 0.275 & 4 & 0.256 & 4 & 0.225 & 6 \\
\hline
\end{tabular}

RMSE: Root mean square of error 
Table 7. Water uptake study at $75 \% \mathrm{RH}$

\begin{tabular}{llll} 
Formulation & With packaging system & Without packaging system & Conclusion \\
\hline SD without sacrificial excipients & $30 \pm 0.23$ & $36 \pm 0.12$ & $\begin{array}{l}\text { Expected conversion of amorphous to crystalline } \\
\text { material is more }\end{array}$ \\
\hline $\begin{array}{l}\text { SD + sacrificial excipients (PGS } \\
\text { and spray-dried lactose) }\end{array}$ & $8 \pm 0.25$ & $17 \pm 0.34$ & $\begin{array}{l}\text { Expected conversion of amorphous to crystalline } \\
\text { material is less }\end{array}$ \\
\hline PGS & $15 \pm 0.15$ & $18 \pm 0.32$ & Higher \% of moisture uptake \\
\hline Spray-dried lactose & $6 \pm 0.35$ & $10 \pm 0.25$ & Higher \% of moisture uptake \\
\hline
\end{tabular}

Table 8. Stability study in presence and absence of sacrificial excipient

\begin{tabular}{|c|c|c|c|}
\hline \multirow{2}{*}{ Formulations } & \multirow{2}{*}{ Time (days) } & \multicolumn{2}{|c|}{ Parameter at $\left(40 \pm 2^{\circ} \mathrm{C} / 75 \pm 5 \% \mathrm{RH}\right)$} \\
\hline & & Drug content & $\%$ CDR \\
\hline \multirow{4}{*}{ Absence of sacrificial excipient } & 0 & $101.6 \pm 0.23$ & $92.88 \pm 0.11$ \\
\hline & 30 & $100.4 \pm 0.11$ & $92.22 \pm 0.21$ \\
\hline & 60 & $98.48 \pm 0.23$ & $90.86 \pm 0.13$ \\
\hline & 90 & $98.08 \pm 0.39$ & $80.32 \pm 0.22$ \\
\hline \multirow{4}{*}{ Presence of sacrificial excipient } & 0 & $101.91 \pm 0.12$ & $92.96 \pm 0.06$ \\
\hline & 30 & $100.2 \pm 0.17$ & $92.12 \pm 0.11$ \\
\hline & 60 & $99.81 \pm 0.13$ & $92.16 \pm 0.16$ \\
\hline & 90 & $99.15 \pm 0.23$ & $91.96 \pm 0.11$ \\
\hline
\end{tabular}

(b) hydrogen bonding between the drug and the polymer; (c) antiplasticizing effect of the polymers. ${ }^{15}$ Therefore, it can be concluded that the sacrificial excipients could be useful to prevent devitrification of an amorphous drug by decreasing the plasticizing effect of adsorbed water.

\section{Stability studies}

The effect of aging on the performance of amorphous ITR was investigated by performing an accelerated dissolution stability study of the optimized formulation over 3 months $\left(40^{\circ} \mathrm{C} / 75 \%\right.$ $\mathrm{RH})$. The results of the evaluation are shown in Table 8.

The solid dispersion containing only plasticizer, i.e., HPMC E5 and Poloxamer 188 , showed less drug release $(80.32 \%$ after 3 months), whereas the solid dispersion with sacrificial excipients, i.e., PGS and spray-dried lactose, showed 91\% drug release after 3 months, which is comparable to its dissolution profile at the time of its manufacture. From the study, it can be inferred that if the formulation is exposed to high humidity the spray-dried lactose and PGS may absorb moisture and therefore less moisture (or no moisture) will be available to the drug. Therefore, the possibility of conversion of drug from amorphous form to crystalline form may be reduced. Thus, it can be concluded that sacrificial excipients play a major role in keeping the drug in amorphous form. ${ }^{16,17}$

\section{CONCLUSIONS}

The results of the present study indicate that the dissolution rate of ITR can be significantly enhanced from its solid dispersion with HPMC E5 and pregelatinized starch. ITR solid dispersion prepared by kneading method showed higher dissolution than the untreated drug. Moreover, the presence of sacrificial excipients like pregelatinized starch and spray-dried lactose in the solid dispersion aided in maintaining the amorphous state of the drug and preventing devitrification during storage, by self-absorption of moisture in place of the drug. As moisture is one of the main reasons for conversion of an amorphous form to crystalline form of a drug during storage, a smart choice of excipients can help in maintaining the drug in amorphous state during long-term storage. The innovative use of pregelatinized starch and spray-dried lactose as sacrificial excipients has not been reported in the literature.

Conflict of Interest: No conflict of interest was declared by the authors.

\section{REFERENCES}

1. Kansara H, Panola R, Mishra A. Techniques used to Enhance Bioavailability of BCS Class II Drugs: A Review. Int J Drug Dev Res. 2015;7:82-93.

2. Vemula VR, Lagishetty V, Lingala S. Solubility enhancement techniques. Int J Pharm Sci Rev Res. 2010;5:41-51.

3. Hart ML, Do DP, Ansari RA, Rizvi AA. Brief Overview of Various Approaches to Enhance Drug Solubility. J Dev Drugs. 2013;2:1-7.

4. Ambike AA, Mahadik KR, Paradkar A. Stability study of amorphous valdecoxib. Int J Pharm. 2014;282:151-162.

5. Shirakura T. Fractional factorial designs of two and three levels. Discrete Math. 1993;116:99-135. 
6. Priyanka W, Sonali BM. Research Paper on Basic of Artificial Neural Network. IJRITCC. 2014;2:96-100.

7. Patel B, Suhagia B, Patel D. Artificial neural network as a tool for Quality by Design in formulation development of solid. Bull Pharm Res. 2015;5:2249-2255.

8. Segale L, Giovannelli L, Mannina P. Formulation and characterization study of itraconazole-loaded microparticles. Pharm Dev Technol. 2015;20:153-158.

9. Meng F, Gala U, Chauhan H. Classification of solid dispersions: correlation to (i) stability and solubility (ii) preparation and characterization techniques. Drug Dev Ind Pharm. 2015;41:1401-1415.

10. United States Pharmacopeia and National Formulary USP 30-NF 25. The United States Pharmacopeial Convention, Inc.: Rockville, MD, 2007:3179-3180.

11. Zhang L, Chai G, Zeng X, He H, Xu H, Tang X. Preparation of fenofibrate immediate-release tablets involving wet grinding for improved bioavailability. Drug Dev Ind Pharm. 2010;36:1054-1063.
12. Zhang L, Chai G, Zeng X, He H, Xu H, Tang X. Preparation of a solid dispersion of felodipine using a solvent wetting method. Eur $\mathrm{J}$ Pharm Biopharm. 2010;36:1054-1063.

13. Furquan A, Sonali J. Improvement of dissolution rate of aceclofenac by solid dispersion technique. Powder Technol. 2011; 207:47-54.

14. Mahesh K, Kataria AB. Solubility and dissolution rate enhancement of itraconazole by solid dispersion technique. Indo Am J Pharm Res. 2014:4:849-863.

15. Jondhale S, Bhise S, Pore Y. Physicochemical Investigations and Stability Studies of Amorphous Gliclazide. AAPS PharmSciTech. 2012;13:448-459.

16. Bronlund J, Paterson T. Moisture sorption isotherms for crystalline, amorphous and predominantly crystalline lactose powders. Int Dairy J. 2004:14:247-254.

17. Dalton CR, Hancock BC. Processing and storage effects on water vapor sorption by some model pharmaceutical solid dosage formulations. Int J Pharm. 1977;156:143-151. 